\title{
Theoretical and Empirical Analysis of Vertical Backward Contracting in Algerian Agriculture
}

\author{
Amine M. Benmehaia ${ }^{1,2}$, Fatima Brabez ${ }^{1}$ \\ ${ }^{1}$ National Higher School of Agronomy, Department of Rural Economics, Avenue Hassan Badi, El Harrach, 16200, Algiers, Algeria \\ ${ }^{2}$ University of Biskra, Department of Agronomy, El Alia City, Biskra, 07004, Algeria
}

\begin{abstract}
The Algerian agricultural sector faces a continuous process of institutional change, which has important consequences on farmers' decision of organizational choices in farming. One of consistent ways to understand this process, and to support related policy making, is by analyzing the determinants of vertical integration of agricultural production. In this study, the determinants of vertical backward integration are analyzed with a maximum-likelihood logistic regression model. By using a farm-level data, the analysis estimates the effect of main factors on the likelihood of a farmer for the backward input contracting. Results suggest that the important factors affecting significantly the farmer's decision for vertical backward integration are farm size, off-farm activities, participation in government programs, ownership structure, and geographical location. The results confirm the effective relationship hypothesized between the likelihood for backward contracting and farm characteristics. Policy implications are drawn for provision of enabling socio economic environment for the performance of agricultural cooperatives.
\end{abstract}

Keywords:backward contract, cooperative, vertical integration, inputs provision, Algeria

\section{Introduction}

The modern economic theory focuses mainly on the study of governance structures in their determinants and effects on the whole economy. This it was claimed in the line of thought recapitalized by Williamson [37][38]. The choice of contract and their structures, especially in agriculture, take increasingly more attention in empirical studies, because agricultural production is becoming more specialized and dependent on outsourcing inputs and services (Cook et al. [9]). Recent studies in New Institutional Economics predict that the realization of processing production efficiencies from using more consistent inputs push toward greater control and coordination (Sykuta and Cook [36]).

As obviously observed in Algerian case, informal production contracts are an important case of the vertical coordination that increasingly characterizes the Algerian agriculture. This re-search proposes a theoretical framework using an intermediary model of backward contracting in inputs. Under the intermediary model, there are at least three parties to the contract arrangement, a processor contracts formally with an intermediary (or cooperative) who then informally contracts with farmers. Farmers engage in backward contracting because they can obtain higher profits. Backward contracting also provides them a certain access to inputs and technical assistance (Bijman [7]).

Indeed, using the cooperative as an intermediary in agricultural input market allows us an understanding of the vertical integration process and its determinants. As admitted in recent literature, an increased concentration, both up and downstream, raises the specter of the traditional cooperative role of counterbalancing market power. However, increasing demands for coordination among layers throughout the agrifood system point to a different role in which cooperative organizations may have a unique advantage (Sykuta and Cook [36]). Generally, farmers choose to backward contract their inputs for two basic reasons. First, to reduce the input price risks (Perry [31]; Cook et al. [9]). The initiative to establish a contract farming scheme usually comes from the contractor, seeking to improve the supply of homogeneous (high) quality products and to increase capacity utilization of specific assets (Bijman, 2008). Second, is to facilitate coordination among farmers. Rest to identify the determinants of backward contracting regarding the economic and social environment settings of Algerian farmers. It might be useful to conceptualizing policy issues related to vertical integration and contracting in the agrifood industry ( $\mathrm{Wu}[39])$

This study aims to understand why Algerian agricultural producers choose to integrate partially by backward input contracting within an intermediate cooperative by analyzing empirically the determinants of vertical backward contracting for inputs provision in Algeria.

\section{Literature Survey}

As admitted in modern economic theory, incentives for vertical integration may arise from the existence of technological or transactional economies or from market imperfections (Frank and Henderson [10]; Perry [31]; Katz [22]; Grega [13]; Cook et al.[9]; Royer [32]; Allen and Lueck [2]). The contracts are chosen to maximize the expected value of the relationship, and they serve primarily to reduce measurement costs and mitigate moral hazard problems, as claimed by Allen and Lueck [2].

More advanced theories in industrial economics claim that vertical contractual relationships arise generally in intermediate good markets. In the agricultural production, farmers purchase their inputs through several contractual structures. One of the aspects of vertical integration in agricultural production implies the intervention of intermediaries like cooperatives. However, resorting to an agricultural cooperative is a common form of vertical integration (Sumner and Wolf [35]). In other words, contracts represent intermediate forms of vertical control (Sexton [33]). Conceptually, farmer-

\section{Volume 6 Issue 1, January 2017




\section{International Journal of Science and Research (IJSR) \\ ISSN (Online): 2319-7064 \\ Index Copernicus Value (2015): 78.96 | Impact Factor (2015): 6.391}

processor relationships comprise a continuum with pure spot markets at one extreme, and farmer-processor vertical integration at the other extreme (Sexton and Lavoie [34]). As backward contracting has become more important for the agrifood industry in developing countries, there is a demand for better insight about the determinants of backward contracting for farmers and contractors, as well as in the conditions under which backward contracting works both efficient and fair (Bijman [7]). Furthermore, vertical contracting may reduce the transaction costs compared to a spot market arrangement (Mishra and Perry [28]; Perry [31]; Bijman [7]). Next section describes some further factors that can determine the structure of vertical backward contracting in agricultural production.

Concerning farm size, despite the different empirical measures, many studies claim its importance for farm production efficiency. In relation with the farm nature, the debate has be-come more ambiguous. In part, it is found that farm size is not related to the probability of contracting (Miyata et al., [29]). On the other hand, Sumner and Wolf [35], through several farm size measures, they have found from the study of dairy farms that vertical integration relates systematically to variation in dairy farm size. Besides, in his study of food manufacturers, Bhuyan [6] has found a negative effect of farm size on the vertical integration. As hypothesis that aims to confirm this research, Mishra and Perry [28]; Goodwin and Schroeder [11]; and Kilmer [24]; Key [23]; and Kilmer et al. [25] concluded that: there is a positive relation between the farm size and the likelihood for backward contracting.

Furthermore, government programs are intended to decrease agricultural producers' risks (Goodwin and Schroeder [11]). As reported in recent empirical studies, government programs have been identified as the primary risk-reducing mechanism for farmers (Mishra and Perry [28]; Baxter et al. [3]). In this direction, it is hypothesized that: the participation in government programs has a significant positive effect on the likelihood for vertical backward contracting. Moreover, it is hypothesized that: farmer's off-farm activity would have a positive significant effect, as predicted in several previous studies.

The diversification may be defined as the presence of multiple agricultural products with distinct marketed outputs in a single management unit. The benefits of diversification are significant in agriculture, while it is considered as the available risk management device for an Algerian farmer (Benmehaia and Brabez [4]). Indeed, diversification would favor vertical integration (Perry [31]). Mishra and Perry [28] concluded that diversification is not significantly related to the adoption of vertical contracting. Whereas Sumner and Wolf [35] have found that it has a negative effect on the likelihood for vertical contracting. The debate is nevertheless ambiguous regardless the nature of agricultural production. However, agricultural products attributes might influence the relative costs of coordination instruments (Hueth and Ligon [18]). For this reason, including agricultural product's nature should be recommended to conclude the effect's direction. It is hypothesized that the diversification of agricultural production reduces the likelihood for vertical backward contracting.
The age of the farmer may be an indication for experience. Some studies assert that the older farmers are more inefficient than the younger ones (young farmers are working more efficient than older ones who are unable to adopt technical innovations). On the other hand, older farmers are more experienced and take profit of their knowledge to use inputs more efficiently. Small farmers in developing countries face constraints that limit their potential to increase productivity and income. They generally prefer to assure themselves a minimum supply of food before expanding commercial production for an uncertain market (Bijman [7]). Smaller livestock farms are less scale and technically efficient than larger farms, where an increased contract use augment the inputsaving associated with these efficiencies, the separate magnitude of these impacts is quite small (Morrison et al. [30]). It is hypothesized that: the farmer's age has a significant positive effect on the likelihood for vertical backward contracting. Moreover, the investment in formal education can be seen as a strategy to improve agricultural productivity, and it can reflect someway the human capital. It would be that educated farmers are expected to have more skills to run their farm more efficiently independently. So, the lack of skills and information would be incentive to cooperate for counterbalancing market power. Indeed, more educated farmers do not have incentives to cooperate. It is hypothesized that: the farmer's human capital reduces the likelihood for backward contracting.

The impact of organizational type on efficiency is in particular an important issue in transitional economics. However, examining efficiency implications for contracting parties depend on the ownership structure of the contractor (Sykuta and Cook [36]). On the other hand, Hueth and Melkonyan [19] have focused on the response of ownership allocations to changing agricultural technologies and food policies in specific commodities. In fact, farm production is frequently carried out by relatively small typically family-operated units in developing countries, as observed in Algerian case. Allen and Lueck [1] concluded that family operation is efficient, and tends to dominate other forms of farm-level organization, because production uncertainty and seasonality in farming (which generate unpredictable and lumpy labor demand). On the other hand, owner operation is an important attribute of farm-level organization. In this case, asset ownership by the farmer provides residual property rights (Grossman and Hart [14]) allowing discretion in choosing whether or not to contract with the intermediary. Whereas asset ownership by the intermediary provides control rights allowing discretion in how to best use the physical assets (Hueth and Melkonyan [19]). When the intermediary owns farm-level assets, the benefits from monitoring are relatively high because farmers internalize fewer non-contractible elements of total farm value. Moreover, a monitor, if one is used, allows an intermediary to more accurately measure a farmers' performance. Intermediary ownership is favored when it affords the intermediary an opportunity to monitor the farmer, and when the intermediary can easily substitute for the farmer's investment (Hueth and Melkonyan [19]). Hendrikse and Bijman [15] found that the response of more vertical coordination entails a higher level of asset specificity. Asset ownership has an effect on agents' incentives to invest in vertical contracting. The bargaining power in this renegotiation process is determined by the ownership of assets. However, this research

Volume 6 Issue 1, January 2017

www.ijsr.net

Licensed Under Creative Commons Attribution CC BY 


\section{International Journal of Science and Research (IJSR) \\ ISSN (Online): 2319-7064}

Index Copernicus Value (2015): 78.96 | Impact Factor (2015): 6.391

asserts that the differences in contract form will be directly related to the nature of the contractors' organizational structures and the incentives they create (Sykuta and Cook [36]). It is hypothesized that: farmer's decision for vertical backward contracting varied significantly through the ownership forms.Finally, the regional differences should reflect the social, economic, and geographic environment differences (including customs, vocations, soil productivity, infrastructures, and transportation). Indeed, contract structures within a given contract environment tend to vary significantly. The location is a factor in explaining differences in efficiency, which links the farm location to environmental characteristics. It is hypothesized that: the likelihood for vertical backward contracting is affected significantly by famers' differences in environment.

\section{Theoretical Framework}

The study considers an economy within a farmer producing a single output which may vary in quantity $Q$ using a single input quantity $X$, and denoting $\mathrm{p}$ the price of farm output (where the model assumes that the farmer is a price taker in a competitive market of output). The model assumes that this input is produced by a firm under an imperfect market involving an input price w. The distribution function of farmer's output is $F(Q \mid w)$ where $Q$ assumed to be independent of $w$ and has a density function $f(Q \mid w)$ supposed a continuously differentiable of $w$. The farmer can influence the distribution of his output by an ex-ante investment in input denoted $s(X)$.

This model introduces a third actor which will reflect an intermediary. In this case it represents an agricultural cooperative reflecting a possibility to collude on the investment input to face the firm's pricing system. The intermediary cooperative becomes a kind of contractual arrangement to support risks by a long run contracts. The cooperative should offer to farmer the same input produced by the firm. The model assumes that the intermediary is free to specify a different payment to the farmer for every realization of $Q$, denoted $v(Q)$.Indeed, farmers and intermediary cooperative would settle a contractual arrangement on the level of this investment.

The farmer's decision problem is to choose between purchasing input from the firm by spot market or by purchasing it from an intermediary cooperative by backward contract. The supplied input quantity $X$ can include in the general case, a proportion $\alpha$ (where $0 \leq \alpha \leq 1$ ).

Thus, the model should suppose that there is a spectrum of contracts choice offered to farmer for purchasing input. The extremes of this interval here reflect two situations that farmers opt for, when $\alpha=0$, means that the farmer uses only the spot market choice, and when $\alpha=1$, means that the farmer uses exclusively the backward contract choice. Indeed, the farmer should choose $\alpha$ that maximizes his expected utility of profit

$$
\Pi=p Q-\alpha v\left(q_{1}\right)-(1-\alpha) w\left(q_{2}\right)
$$

Where $q_{1}$ and $q_{2}$ are input quantities purchased from backward contract (intermediary cooperative) and spot market (upstream firm) respectively. The model has implicitly the total amount of input $X$ as

$$
X=q_{1}+q_{2}
$$

Furthermore, for simplicity, the farmer's choice have an investment cost involving from the two polar contracting cases denoted $v(X)$ when farmer full-purchases from his cooperative, $w(X)$ when he purchases all his $X$ from spot market. Here, the amount of returns from the choice of both contracting denoted $z \in Z$, is:

$$
z=v\left(q_{1}\right)-w\left(q_{2}\right) \text { where } z \sim \mathcal{N}\left(0, \sigma^{2}\right)
$$

The model assumes also that returns $z$ have an expected utility function such as

$$
E U(z, z \in Z)=h\left(z \mid C_{i}\right)
$$

where $C_{i}$ reflects the main characteristics of the farm. The question here is to confirm the relationship that could be exists between the returns from backward contracts and the marginal benefit of an increase in ex-ante investment? and which of the main characteristics have an influence on adopting a backward integrate contract? The answer requires some theoretical developments.

This study will model first the situation that the farmer opts for the choice of purchasing input only through spot market. His problem here is to choose $\mathrm{w}$ so as to maximize his expected utility

$$
\max _{w} \int U[p Q-w(X)] f(Q \mid w) d Q
$$

This involves that the farmer chooses $\mathrm{w}(\mathrm{X})$ so as to satisfy

$$
\begin{gathered}
\int U^{\prime}[p Q-w(X)] f(Q \mid w) d Q= \\
\int U[p Q-w(X)] \frac{f_{w}(Q \mid w)}{f(Q \mid w)} f(Q \mid w) d Q
\end{gathered}
$$

The classical interpretation of this expression is that the lefthand side reflects the expected marginal costs of investing $w(X)$, while the right-hand side reflects the expected marginal benefits. Thus, benefits can be estimated by the likelihood ratio $L$ as

$$
\mathcal{L}=\frac{f_{w}(Q \mid w)}{f(Q \mid w)}
$$

Here and for this case, the farmer supports all risk, because its show that his benefit is directly dependent on the level on his investment in input without a complete insurance against risks issued from all imperfection of the market.

In the second, the study models the situation where the farmer has the choice to contract with the intermediate cooperative. Hence, perhaps the study should admit that an intermediate cooperative nature in the proposed economy is to face and support risks with farmers as device to handle the market imperfections. Thus, the intermediate cooperative design contract through the following problem

$$
\max _{w, v} \int\left[p Q-v\left(q_{1}\right)\right] f(Q \mid w) d Q
$$

subject to

$$
\int U\left[v\left(q_{1}\right)-w\left(q_{2}\right)\right] f(Q \mid w) d Q \geq \underline{U}
$$

This is a classical problem that involves a solution by using the first order conditions. But the purpose is curiously shown by the solution equating the marginal benefit and the La-

\section{Volume 6 Issue 1, January 2017}




\section{International Journal of Science and Research (IJSR) \\ ISSN (Online): 2319-7064}

Index Copernicus Value (2015): 78.96 | Impact Factor (2015): 6.391

grange multiplier associated with the latter constraint. So, it is obtained

$$
\int p Q \frac{f_{w}(Q \mid w)}{f(Q \mid w)} f(Q \mid w) d Q=\frac{1}{U^{\prime}(z)}
$$

This expression here has a basic interpretation. The left-hand side, is a measure of the marginal benefit of an increase in investment $w\left(q_{2}\right)$, while the right-hand side, another measure of the marginal costs associated with cooperative's compensation for the farmer for an increase in investment $v\left(q_{1}\right)$.

Here, as developed above, it can be concluded that there is a kind of relationship between the likelihood ratio reflecting farmers' benefits and the returns utility from contracting (we mention that the results founded here are accordingly consistent with previous modeling in such case. The authors note that the theoretical developments here corresponds the conceptual findings in accordance to Hueth and Ligon Hueth et al. [21]; [18]; Mishra and Perry [28]; Hueth and Hennessy [17]; Ligon [26]). The maximization of the expected utility of benefits yields an expression relating a farmer's adoption of forward contracting of inputs through an intermediary cooperative, represented by $\alpha$, to a set of observable farm characteristics $\left(C_{i}\right)$, such as

$$
\alpha=h\left(\beta C_{i}\right)+\xi_{i}
$$

where $\beta$ is a parameter vector, and $\xi_{i}$ represents unmeasured factors related to backward contracting. Because $\alpha$ is unobservable, it will estimate by a discrete choice for binary variable. Hence, the study propose the following model:

$$
Y_{i}=\beta C_{i}+\gamma_{i}
$$

where $Y_{i}$ equal 1 if $\alpha>0$, and 0 otherwise, and $\gamma_{i}$ is the residual error.

\section{Research Methodology}

\subsection{Data}

Data for this analysis are derived from the Regional Sample Survey provided by the National Research Program on Farming and Agricultural Cooperatives over the period 20132015. The data were collected through detailed interviews realized across a randomly selected 650 farmers. A questionnaire was developed and was well adapted to the farmers. The survey collects data capturing the main agricultural producers' characteristics (farming activities, economic and social environments). The data consists of several versions that can be used separately to analyze a particular issue. So, by focusing on vertical backward contracts, farmers were given their backward strategies and asked to identify their uses of these strategies. Interviews with farmers allowed us to define the upstream stage of production. Therefore, the data used here is adapted for selected variables that deal with the vertical backward contracting.

\subsection{Dependent variable}

Maximum-likelihood logistic regression (Logit) is employed to analyze the use of backward input contracting because the dependent variable is binary. The interpretation of this model based on the guidebook of Hosmer and Lemeshow [16]. The dependent variable, BACKWARD (Yi), takes a value of 1 if the farmer uses the backward contracting of inputs via an intermediate cooperative and assumes a value of zero if he choose the spot markets

$Y_{i}=\{1,0\} \quad$ where 1 if participates, 0 for spot markets The Logit is defined as the natural logarithmic value of the odds in favor of a positive response (Greene [12]; Hosmer and Lemeshow [16]). Consequently, the marginal effect on the likelihood for $B A C K W A R D$ (1), i.e. on the choice of backward contracting.

\subsection{Explanatory variables}

The explanatory variables in the econometric modeling are divided into three sets. The first reflects the farmer's characteristics, the second, ownership forms, and the third, regional location. Table 1 gives the definitions and mean values of the explanatory variables and of the binary dependent variable $B A C K W A R D$

The variable of age $(A G E)$ is captured by a quantitative variable indicating the farmer's age in number of years. The farmer's non-agricultural occupation is represented by a dummy variable (OFF FARM), which takes the value of 1 if farmer have another non-agricultural occupation, 0 if he have only his farming activity. The participation in government programs is included in the analysis via a dummy variable $(G O V P G M)$. It takes the value of 1 if the farmer participates in government programs, and takes the value 0 if he doesn't. Farm size (FSIZE) is captured by land dimension criteria that measure the cultivated land area (in hectares).

The farm activity diversification (DIVERS) measured by a binary variable, taking the value of 1 if farmers diversify their production (more than one product), and takes the value of 0 if the farmer is specialized in one agricultural product. In order to consider the nature of the agricultural activities, 8 dummy variables was emitted to reflect the main activities: the beef for dairy farming $(D B E E F)$, the beef or sheep farming $(B E E F)$, the goat for dairy farming $(D G O A T)$, the goat farming $(G O A T)$, the eggs in poultry farming (EGGS), the poultry farming (POULTRY), the hive farming (HIVE), and finally, grain and cereal farming (GRAIN).

The farmer's human capital is incorporated in the model with a design variable reflecting the formal educational qualification, indicated by three dummies (INSTRUC1, INTRUC2 and INSTRUC3). The first takes value of 1 , if the farmer has no educational qualification, 0 otherwise. The second takes the value of 1 , if the farmer has a basic education degree, 0 otherwise. The third takes 1 if the farmer has a higher education degree, 0 otherwise. The study does not include a reference dummy because the intercept does not included in the model. 


\section{International Journal of Science and Research (IJSR)}

ISSN (Online): 2319-7064

Index Copernicus Value (2015): 78.96 | Impact Factor (2015): 6.391

Table 1: Definitions and mean values of variables used in the model

\begin{tabular}{|c|c|c|c|}
\hline Variable Name & Variable Description & Mean & S.D \\
\hline \multicolumn{4}{|c|}{ Dependent Variable: } \\
\hline$B A C K W A R D$ & 1 if farmer uses backward contracting of inputs, 0 otherwise & 0.39 & 0.49 \\
\hline \multicolumn{4}{|c|}{ Explanatory Variables: } \\
\hline$A G E$ & Age of the farmer (years) & 52.36 & 13.17 \\
\hline OFF FARM & 1 if farmer participated in off-farm work, 0 otherwise & 0.19 & 0.39 \\
\hline DIVERS & 1 if farmer diversify their production, 0 otherwise & 0.52 & 0.50 \\
\hline GOVPGM & 1 if farmer participated in government program, 0 otherwise & 0.43 & 0.49 \\
\hline FSIZE & Cultivated land area (hectares) & 16.9 & 27.48 \\
\hline INSTRUC1 & 1 if farmer has no educational qualification, 0 otherwise & 0.76 & 0.42 \\
\hline INSTRUC2 & 1 if farmer has secondary education degree, 0 otherwise & 0.14 & 0.35 \\
\hline INSTRUC3 & 1 if farmer has higher education degree, 0 otherwise & 0.90 & 0.29 \\
\hline EASTDZ & 1 if farm is located in Northeast, 0 otherwise & 0.31 & 0.46 \\
\hline$M I D D Z$ & 1 if farm is located in North-middle, 0 otherwise & 0.39 & 0.49 \\
\hline WESTDZ & 1 if farm is located in Northwest, 0 otherwise & 0.30 & 0.46 \\
\hline RENTLAND & 1 if farmer operates on leased land, 0 otherwise & 0.40 & 0.19 \\
\hline COLLAND & 1 if farmer operates on collective ownership, 0 otherwise & 0.32 & 0.47 \\
\hline FAMLAND & 1 if farmer operates on family ownership land, 0 otherwise & 0.64 & 0.48 \\
\hline$D B E E F$ & 1 if classified as beef for dairy farm, 0 otherwise & 0.40 & 0.49 \\
\hline$B E E F$ & 1 if classified as, beef or sheep farm 0 otherwise & 0.22 & 0.41 \\
\hline$D G O A T$ & 1 if classified as goat for dairy farm, 0 otherwise & 0.22 & 0.42 \\
\hline GOAT & 1 if classified as goat farm, 0 otherwise & 0.11 & 0.31 \\
\hline$E G G S$ & 1 if classified as eggs in poultry farm, 0 otherwise & 0.40 & 0.19 \\
\hline POULTRY & 1 if classified as poultry farm, 0 otherwise & 0.11 & 0.31 \\
\hline HIVE & 1 if classified as hive farm, 0 otherwise & 0.13 & 0.34 \\
\hline GRAIN & 1 if classified as grain farm, 0 otherwise & 0.74 & 0.44 \\
\hline
\end{tabular}

Regional dummy variables are incorporated for factors such as soil productivity, climate variations, and social environment that may impact the choice of backward contracting. The re-search selects EASTDZ, MIDDZ, and WESTDZ to represent respectively the East, the Center, and the West.

Likewise, the main ownership forms are included by a design variable without reference category. The three forms are: Rented lands (RENTLAND), collective owned lands (COLLAND), and family owned lands (FAMLAND).

Finally, with all this variables, the study will proceed a logistic regression resulting qualitative conclusions on the determinants of backward contracting of production in Algeria.

\section{Empirical Results}

This study aims to understand why Algerian agricultural producers choose to integrate partially by backward input contracting within an intermediate cooperative. This section presents now the main empirical results through the analysis of model issue from the selected data. The robustness and effectiveness of the modeling developed are demonstrated, and the colinearity diagnoses pose no difficulties. Now, some descriptive statistics of sample are shown, which can reflect the main characteristics of an agrarian economy and defining a background of farming activity in Algerian settings.

From the Table 1, the mean of the dependent variable, $B A C K W A R D$, is 0.39 , which means that from the total, $39 \%$ of farmers are vertically backward integrated (with standard deviation of 0.49 ). This seems to be representative to con- clude on the determinants of backward contracting practices relative to sample size. Regarding the famer's age, it seems that the representative farmer is an old man (a mean of 52 years) and the farming activities are held by old farmer (standard deviation of 13.17). This means that the Algerian farmers have an old age and the younger entrepreneurs in farming are moved out from agricultural activities. In addition, he statistics shows a mean of 0.19 for the farm-off variable, which means that $19 \%$ of farmers having nonagricultural occupations (high standard deviation: 0.39).

In the sample, $52 \%$ of farmers who diversify their production. Indeed, from the nature of their production, the study reveals the main farming activities: the grain and cereal farming (74\%) and dairy farming (40\%) (We note that the agricultural activity nature's dummies are not a design variable. The farmer can diversify his productions, i.e. the sum of the eight dummies do not necessary equal one). The participation in government programs represents an average of $43 \%$ of farmers with a higher standard deviation which means that farmers are frequently en-gaged with government programs for local development and subsidies. Also, the mean of farm size of 16.9 hectares, with a high standard deviation of 27.48 , which confirms the diversity of the sample in terms of farm size. The human capital dummy contains $76 \%$ of farmers with no educational qualification, $14 \%$ for formers having a basic education degree, and $9 \%$ for whose have a higher education degree. Indeed, if could be considered that INSTRUC1 and INSTRUCT2 reflect the low education level, it confirm that $90 \%$ of farmers with low education level as a dominant social category in farming activities. 


\section{International Journal of Science and Research (IJSR) \\ ISSN (Online): 2319-7064}

Index Copernicus Value (2015): 78.96 | Impact Factor (2015): 6.391

Table 2: Maximum-Likelihood Estimates of the Logit Model for Farmer's Characteristics from the NRP Survey (Standard errors based on Hessian)

\begin{tabular}{|c|c|c|c|c|c|}
\hline Variables & Coefficient & z-value & Variables & Coefficient & z-value \\
\hline$A G E$ & $0.043(0.006)$ & $\uparrow 6.92$ & $D B E E F$ & $-0.999(0.232)$ & $\dagger-4.308$ \\
\hline FARMOFF & $0.973(0.189)$ & $\dagger 5.132$ & $B E E F$ & $0.143(0.256)$ & 0.558 \\
\hline DIVERS & $-1.111(0.258)$ & $\dagger-4.3$ & $D G O A T$ & $1.34(0.251)$ & $\dagger 5.34$ \\
\hline GOVPGM & $2.408(0.145)$ & $\dagger 16.595$ & GOAT & $-0.2(0.3)$ & $\dagger-0.668$ \\
\hline FSIZE & $-0.007(0.002)$ & $\dagger-3.123$ & $E G G S$ & $2.957(0.47)$ & +6.282 \\
\hline INSTRUCI & $-3.1(0.4)$ & $\dagger-7.74$ & POULTRY & $0.816(0.252)$ & $\uparrow 3.231$ \\
\hline INSTRUC2 & $-3.349(0.405)$ & $\dagger-8.251$ & HIVE & $2.032(0.229)$ & $\uparrow 8.835$ \\
\hline INSTRUC3 & $-3.512(0.477)$ & $\dagger-7.356$ & GRAIN & $-1.004(0.205)$ & $\dagger-4.899$ \\
\hline FAMLAND & $-0.007(0.061)$ & -0.123 & MIDDZ & $-0.978(0.088)$ & $\dagger-11.101$ \\
\hline RENLAND & $-0.669(0.268)$ & $\dagger \dagger-2.493$ & EASTDZ & $-0.554(0.091)$ & $\dagger-6.033$ \\
\hline COLLAND & $-1.591(0.115)$ & $\dagger-13.762$ & WESTDZ & $0.228(0.09)$ & $\dagger+2.519$ \\
\hline \multicolumn{3}{|c|}{ McFadden R-squared $=0.379$} & \multicolumn{3}{|c|}{ Cases correctly predicted $=539(82.8 \%)$} \\
\hline \multicolumn{3}{|c|}{ Log-likelihood $=-267.93$} & \multicolumn{3}{|c|}{ Likelihood ratio test: $\chi^{2}(21)=816.09[0.0000]$} \\
\hline
\end{tabular}

Note: The dagger and double dagger symbols $(\dagger \dagger)$ denote parameter error significance at $.1 \%$ and $5 \%$ respectively; no symbol denotes high parameter error significance than $10 \%$. Standard errors are shown in parentheses.

Furthermore, it seems that the farmers' locations are relatively uniformly distributed in the sample. The study has $31 \%$ from the East, 39\% from the Middle, and 30\% from the West of the country. In terms of the ownership forms, apparently the family ownership is the dominant form with an average of $64 \%$, the second dominant form is the collective ownership (32\%), then come the leasing land which is not the prevailing mode in farming due to the limited land markets according to the economic environment settings.

\subsection{Farmer's Characteristics Analysis}

The maximum-likelihood estimates of the Logit model (summarized in Table 2) proves to be well suited to analyzing the vertical integration by backward contracting in farms, with $82.8 \%$ of predicted values. The McFadden coefficient value of 0.37 is acceptably high, particularly for Logit models. The regression likelihood ratio test specified via $\chi^{2}$ (816.09, with 21 degrees of freedom), which tests the overall significance of the model, is significant at the $0.1 \%$ level. The first parameter, contrary to some previous studies, the estimated coefficient for age $(A G E)$ is positive; however, it is significant in the model. This means that the farmer's age has a positive significant effect on the likelihood for backward contracting. Accordingly, older is the farmer, more is his aversion toward risks, consequently, more likely to backward contracts his inputs. Moreover, the coefficient estimates for the off-farm occupations is positive and significantly different from zero (0.97 with z-value of0.18). This confirms in fact that farmers whose have a non-agricultural occupation are more likely to backward contracting.

Agricultural production diversification (DIVERS) is also significantly related to the adoption of backward input contracting. The coefficient estimate is negative, which means that the agricultural production diversification affect negatively the likelihood for backward contracting. This variable presumably can proxy the horizontal integration of production. Therefore, the study can affirm that the horizontal integration of production reduces the likelihood for vertical backward integration.

Indeed, by examining the nature of activities that can be horizontally integrated, it shows that all activities have a signif- icant effect, except for beef and goat farming. The activities having a higher marginal effect on the likelihood of backward contracting are eggs production farming, then the hive farming with 2.95 and 2.03 with extremely higher $z$-values of 6.28 and 8.83 respectively, when the poultry and goat dairy farming are less likely to integrate with 1.340 and 0.816 as positive coefficient estimates (5.340 and 3.231 as high z-values). Whereas the likelihood of backward contracting is awfully reduced in grain, cereal, and beef dairy farming with insignificant marginal effects.

The estimated coefficient for the farmer's participation in government programs (GOVPGM) is positive and significantly different from zero. It seems to have a high marginal effect (2.4 with z-value of -4.3). Therefore, those farmers who participate in government programs are much more likely to use backward input contracting than those who don't. The estimated coefficient for the effect of farm size is significant, but having the value of -0.007 (with a high $\mathrm{z}$-value) means that the likelihood for vertical backward integration increase smoothly with the farm size. It confirms that higher is the farm size, less significant is the marginal effect on the likelihood for vertical backward contracting.

The farmer's education level, as a proxy for human capital, has negative coefficient estimates with a strong significance level. The de-creasing values of coefficients, from low education to the higher, means that the education level reduces the likelihood for backward integration but with insignificant marginal effect.

\subsection{Farm's Ownership Analysis}

In addition of farmer's characteristics, the effect of farm ownership forms on the likelihood of backward contracting is included in the model. The coefficients estimates for ownership forms apparently have a relative significant marginal effect in the model. The model cannot confirm the fact that the family farming is more likely to vertical backward contracting, because it present non-significant error level for its coefficient estimates (Higher than 10\%). Hence, despite the coefficient estimates for a rented land has significance at $5 \%$, it represents the higher marginal effect through the three forms. Which is obviously clear is the negative effect of the 


\section{International Journal of Science and Research (IJSR) \\ ISSN (Online): 2319-7064}

Index Copernicus Value (2015): 78.96 | Impact Factor (2015): 6.391

collective ownership form with coefficient estimates of -1.56 (higher z-value, -13.7).

Therefore, regardless the difficulties to interpret the two first forms, the model asserts that the collective ownership form reduces the likelihood for backward integration, and at the significance level of $5 \%$, the model confirm also that the leasing form has the highest positive effect on the likelihood for backward contracting.

\subsection{Regional Analysis}

The study turns now, and finally, to analyze the likelihood for vertical backward contracting in terms of regional locations. The coefficient estimates for the Middle and the East of the country are negative with significance at $1 \%$ (with a higher z-value: -11.1 and -6.03 respectively). They seem to have an insignificant marginal effect on the likelihood for vertical backward contracting.

Nevertheless, the West seems to have a large marginal effect with a positive coefficient estimate, but at significance at $5 \%$, (with a relative high z-value 2.51). Western farms are more likely to use forward input contracting. Consequently, the model af-firms that the large differences in social and economic environments through these regions tend to influence the likelihood for vertical backward contracting.

\section{Discussion and Policy Implications}

This article analyzes data on several farms' characteristics and the determinants of vertical backward contracting by an intermediate cooperative from a large sample of Algerian farmers. Vertical backward contracting was associated significantly with the farmer's age, the farm size and off-farm activity, and the most important is with the farmer's participation in government commodity programs which have a high marginal effect. Similar conclusions are corroborated from the studies conducted by Mishra and Perry [28]; Goodwin and Schroeder [11]; Kilmer [24]; Key [23]; Kilmer et al. [25]; Benmehaia and Brabez [5]; and Allen and Lueck [1]. In contrast, backward contracting appears to be insignificantly associated with the human capital and farm product diversification dummies.

Given the off-farm marginal effect, agricultural producer with higher levels of off-farm activities backward contracts at higher levels than those producers whose income is totally dependent on the income they receive from merely farming activities. As a result, the model explains the opportunism nature in transaction postulated in facts and theoretical frameworks. Having a positive effect means that extending for off-farming activities lead toward diversifying farmers' portfolios as a device for reducing production risks from farming activities.

Size of farm operation (as measured by cultivated land area), suggesting the presence of economies of scale, also played an important role. According to transaction cost reasoning, the incentive for vertical integration is negated by strong diseconomies of scale, supporting those diseconomies of scale could be a factor limiting the extent of vertical integration (Williamson [37]). The economic significance of back- ward integration potentiality with inputs producers may reside in the convenience to manage directly agricultural input industry on a larger scale. Model results suggest also that for the use of backward contracting of inputs, the participation in government commodity programs is the higher significant factor affecting the likelihood of using backward input contracts representing here the higher marginal effect, which remain the major interesting determinant (Chagwiza et al. [8]).

The farm product diversification is found to have a low marginal effect on the vertical backward contracting. Indeed, this would be confirmed by the hypothesis that the horizontal integration reduces the likelihood for vertical integration. In contrast, the farm product diversification dummy can reflect somehow the farm specialization for an agricultural product. More diversified farm means less specialized, consequently the model shows an inverse marginal effect in term of specialization. The empirical evidence suggests that the farm specialization has a positive effect on the likelihood for the vertical backward contracting. The reason for the negative marginal effect of diversification dummy used here is simply that it doesn't take into account each activity nature. By doing so, it will obtain a more straightforward interpretation of this finding. On the other hand, an additional finding, according to the conceptual framework presented here, suggests that changes in agricultural product characteristics alter the characteristics of the transaction, resulting in closer vertical relationships between farmers and intermediate cooperative. Farms specialized in eggs and hive production, poultry and dairy goat farming respectively are the more likely to use backward contracting than farms specializing in dairy beef and grain farming.

Empirical evidence suggests also that internalization of input purchase transactions for different farming activities by farmers having limited schooling (average schooling is less than secondary education level) is found to be correlated with vertical backward contracting. The reason for the negative relationship between backward contracting and formal education is that more educated farmers are expected to be more likely to ensure themselves the input purchasing transactions. From the farm ownership side, the rented land has obviously the higher likelihood for the vertical backward contracting than other forms. But because the underdeveloped land markets in the Algerian economic settings, the family farms rest the most common efficient structure for the extent of farming activities. The finding here is the inefficiencies in collective farms, which present lower likelihood for the backward contracting. Indeed, in order to reveal the effect of farm ownership, the model claim that the backward contracts can combine the economies of size which are essential to compete in modern agriculture generating the social advantages of family farms.

Finally, geographic location was also an important variable, with farmers in the West are more likely to use backward input contracting relative to farmers in the other regions. Differences in regional geographic location have a low marginal effect on the backward contracting because there is a relative tight difference in socio-economic environments. This finding is not surprising because farms in the West tend to specialize in grain farming. This could be explained by the 


\section{International Journal of Science and Research (IJSR) \\ ISSN (Online): 2319-7064}

Index Copernicus Value (2015): 78.96 | Impact Factor (2015): 6.391

agricultural vocation that has the West in some farming activities. In addition, this could reflect the role and effectiveness of agricultural cooperatives in different environments confirming that it matters to reach for the economic efficiency for such organizational choices.

This analysis aims to point out the fact that in Algeria the current regulated input distribution system has been established in Algeria for relatively homogenous agricultural commodities. One of the justifications for this institution is that market failure results in an underinvestment in market development and promotion because of the unbranded, commodity nature of the products.

This study represents the first known attempt to quantify the determinants of backward integration in Algerian agricultural markets. The results confirm the effective relationship hypothesized between the likelihood for backward contracting and farm characteristics. As stated by MacDonald et al. [27], the forces underlying agricultural industrialization affect the design and impact of, and support for, various public policies in agriculture. In order to enhance an efficient food safety policy, first, this research emphasizes that more intensive monitoring of farm-level behavior is required, at second, seeking for more efficient production and distribution structures, agricultural cooperatives can provide a new window into the effect of organization choices on welfare metrics.

The analysis presented here leaves unanswered some interesting questions about organizational choices. As stated by Hueth et al. [20], variation in contract terms across individual growers seems necessary but not sufficient. This study focused on vertical backward contracting decisions in different farming activities. Thus, conclusions and inferences about the results may be limited to this setting and may not address vertical integration choice in other industries. However, the authors believe many of factors that are associated with farm boundaries in the current study can be found in other settings. Some of the limitations of this study suggest important topics for further research. Investigations on strategic motivations may constitute an interesting extension of this analysis.

Future topics research may relay principally on a detailed study of the strong effect of the farmer's participation in government programs and the reverse effect of horizontal integration in agricultural markets. Future studies could devote attention to the importance of the farmers' strategic behaviors considering their perception of the intermediary cooperative and its effective performances and not only considering the farm's characteristics.

\section{Conclusion}

This article analyzes data on several farms' characteristics and the determinants of vertical backward contracting by an intermediate cooperative from a large sample of Algerian farmers. The results offer a useful explanation of the farms' vertical integration trends for Algerian agricultural producers. It was associated significantly with the farm size and offfarm activity, and the most important is with the farmer's participation in government commodity programs. In contrast, it seems to be insignificantly associated with the human capital and farm product diversification dummies. The regional and farm ownership difference state that the role and effectiveness of agricultural cooperatives in different environments matters to reach for the economic efficiency for such organizational choices.

This study represents the first known attempt to quantify the determinants of vertical backward integration in Algerian agricultural markets. The results confirm the effective relationship hypothesized between the likelihood for backward contracting and farm characteristics. It seems that the cooperative can be used to rationalize government involvement for efficient vertical coordination in agriculture. The policy implication of this analysis is the emphasis on the fact that agricultural cooperatives can provide new insights into the determinants of farm's vertical organization choices in order to seek for more efficient production and distribution structures.

\section{References}

[1] Allen, D., and Leuck, D., 1998. The Nature of the Farm. Journal of Law and Economics, XLI(41): 343-386.

[2] Allen, D., and Leuck, D., 2008. Agricultural Contracts. In: Handbook of New Institutional Economics. Springer. 465-490.

[3] Baxter, S., Zulauf, C., Schnitkey, G., and Forster, L., 1996. Corn Program Participation and Farm Program Opinions. Review of Agricultural Economics, 18: 43-51.

[4] Benmehaia, M.A., and Brabez, F., 2016. Determinants of On-Farm Diversification Among Rural Households: Empirical Evidence from Northern Algeria. International Journal of Food and Agricultural Economics, 4 (2): 87-99.

[5] Benmehaia, M.A., and Brabez, F., 2016. The Propensity to Cooperate Among Peasant Farmers in Algeria: An Analysis from Bivariate Approach. International Journal of Food and Agricultural Economics, 4(4): 79-92.

[6] Bhuyan, S., 2005. An Empirical Evaluation of Factors Determining Vertical Integration in U.S. Food Manufacturing Industries. Agribusiness, 21(3): 429-445.

[7] Bijman, J., 2008. Contract Farming in Developing Countries: An Overview. Working Papers, Wageningen University.

[8] Chagwiza, C., Muradian, R., and Ruben, R. (2016). Cooperative membership and dairy performance among smallholders in Ethiopia. Food Policy, 59, 165-173.

[9] Cook, M.L., Klein, P.G., and Iliopoulos, C., 2008. Contracting and Organization in Food and Agriculture. In: New Institutional Economics: A Guidebook. Cambridge University Press. 292-304.

[10] Frank, S.D., and Henderson, D.R., 1992. Transaction Costs as Determinants of Vertical Coordination in the U.S. Food Industries. American Journal of Agricultural Economics, 74(4): 941-950.

[11] Goodwin, B.K., and Schroeder, T.C., 1994. Human Capital, Producer Education Programs, and the Adoption of Forward Pricing Methods. American Journal of Agricultural Economics, 76: 936-947.

[12] Greene, W.H., 2003. Econometric Analysis. 5th ed. Pearson Education. Upper Saddle River. 


\section{International Journal of Science and Research (IJSR) \\ ISSN (Online): 2319-7064 \\ Index Copernicus Value (2015): 78.96 | Impact Factor (2015): 6.391}

[13] Grega, L., 2003. Vertical Integration as a Factor of Competitiveness in Agriculture. Agricultural Economics Czech, 49(11): 520-525.

[14] Grossman, S., and Hart, O., 1986. The Costs and Benefits of Ownership: A Theory of Lateral and Vertical Integration. Journal of Political Economy, 94: 691-719.

[15] Hendrikse, G., and Bijman, J., 2002. Ownership Structure in Agrifood Chains: The Marketing Cooperative. American Journal of Agricultural Economics, 84(1): 104-119.

[16] Hosmer, D.W., and Lemeshow, S., 2000. Applied Logistic Regression. 2nd ed. John Wiley.

[17] Hueth, B., Hennessy, D.A., 2001. Contracts and Risk in Agriculture: Conceptual and Empirical Foundations. SER-IEG-31 Meetings. Golf Shores.

[18] Hueth, B., and Ligon, E., 1999. Producer Price Risk and Quality Measurement. American Journal of Agricultural Economics, 81: 512-524.

[19] Hueth, B., and Melkonyan, T., 2004. Asset Ownership and Incentives in Agricultural Production. In: Exploring Frontiers in Applied Economics: Essays in Honor of Stanley R. Johnson. Berkeley Electronic Press.

[20] Hueth, B., Ligon, E., and Dimitri, C., 2007. Agricultural Contracts: Data and Research Needs. American Journal of Agricultural Economics, 89: 1276-1281.

[21] Hueth, B., Ligon, E., Wolf, S., and Wu, S., 1999. Incentive Instruments in Fruit and Vegetable Contracts: Input Control, Monitoring, Measuring, and Price Risk. Review of Agricultural Economics, 21: 374-89.

[22] Katz, M.L., 1989. Vertical Contractual Relations. In: Handbook of Industrial Organization. Elsevier Science Publishers. 655-721.

[23] Key, N., 2004. Agricultural Contracting and the Scale of Production. Agricultural and Resource Economics Review, 33: 255-271.

[24] Kilmer, R.L., 1986. Vertical Integration in Agricultural and Food Marketing. American Journal of Agricultural Economics, 68(5): 1155-1160.

[25] Kilmer, R.L., Andre, A.M., and Stevens, T.J., 2001. Pesticide Residues and Vertical Integration in Florida Strawberries and Tomatoes. Agribusiness, 17(2): 213226.

[26]Ligon, E., 2003. Optimal Risk in Agricultural Contracts. Agricultural Systems, 75(2): 265-76.

[27] MacDonald, J.M., Ahearn, M.C., and Banker, D., 2004. Organizational Economics in Agriculture Policy Analysis. American Journal of Agricultural Economics, 86(3): 744-749.

[28] Mishra, A.K., and Perry, J.E., 1999. Forward Contracting of Inputs: A farm-Level Analysis. Journal of Agribusiness, 17(2): 77-91.

[29] Miyata, S., Minot, N., and Hu, D., 2009. Impact of Contract Farming on Income: Linking Small Farmers, Packers, and Supermarkets in China. World Development, 37(11): 1781-1790.

[30] Morrison, P.C.J., Nehring, R., and Banker, D., 2004. Productivity, Economies, and Efficiency in U.S. Agriculture: A Look at Contracts. American Journal of Agricultural Economics, 86(5): 1308-1314.

[31] Perry, M.K., 1989. Vertical Integration: Determinants and Effects. In: Handbook of Industrial Organization. Elsevier Publishers. 184-255.
[32] Royer, J.S., 2007. Cooperative Forward Integration in Oligopsonistic Markets: A Simulation Analysis of Incentives and Impacts. In: Vertical Markets and Cooperative Hierarchies. Springer. 169-194.

[33] Sexton, R.J., 2012. Market Power, Misconceptions, and Modern Agricultural Markets. American Journal of Agricultural Economics, 24: 1-11.

[34] Sexton, R.J., and Lavoie, N., 2001. Food Processing and Distribution: An Industrial Organization Approach. In: Handbook of Agricultural Economics. Elsevier Publishers. 863- 932.

[35] Sumner, D.A., and Wolf, C.A., 2002. Diversification, Vertical Integration, and the Regional Pattern of Dairy Farm Size. Review of Agricultural Economics, 24(2): 442-457.

[36] Sykuta, M.E., and Cook, M.L., 2001. A New Institutional Economics Approach to Contracts and Cooperatives. American Journal of Agricultural Economics, 83(5): 1273-1279.

[37] Williamson, O.E., 2002. The Theory of the Firm as Governance Structure: From Choice to Contract. Journal of Economic Perspectives, 16: 171-195.

[38] Williamson, O.E., 2010. Transaction Cost Economics: The Natural Progression. Journal of Retailing, 86(3): 215-226.

[39] Wu, S.Y., 2006. Contract Theory and Agricultural Policy Analysis: A Discussion and Survey of Recent Developments. Australian Journal of Agricultural and Resource Economics, 50:490-509. 